\title{
2-Oxoglutarate-dependent dioxygenases in the biosynthesis of simple coumarins
}

\author{
Bun-Ichi Shimizu* \\ Department of Life Sciences, Graduate School of Life Sciences, Toyo University, Itakura, Japan
}

\section{Edited by:}

Stefan Martens, Edmund Mach

Foundation, Italy

Reviewed by:

Joong-Hoon Ahn, Konkuk University, South Korea

Basil J. Nikolau, lowa State

University, USA

*Correspondence:

Bun-Ichi Shimizu, Department of

Life Sciences, Graduate School of

Life Sciences, Toyo University,

Itakura, Gunma 3740193, Japan

e-mail: bsimz@toyo.jp
Coumarins are natural plant products that have been the subject of extensive phytochemical and pharmacological research studies in the past few decades. The core structure of coumarins is derived from the respective cinnamates via ortho-hydroxylation of the aromatic ring, trans/cis isomerization, and lactonization. Various substitution patterns of coumarins have been reported, whereas the biosynthesis of coumarins remains elusive. Ortho-hydroxylation is a key step in simple coumarin biosynthesis as a branch point from the lignin biosynthetic pathway. 2-Oxoglutarate-dependent dioxygenases (2OGDs) from plants convert cinnamate derivatives into simple coumarins through the process of ortho-hydroxylation. This review describes the 20GDs involved in coumarin biosynthesis and their substrate specificities.

Keywords: coumarin biosynthesis, simple coumarins, Ortho-hydroxylases, coenzyme A thioester of cinnamates, C-terminal sequences, Arabidopsis, Ipomoea batatas, Ruta graveolens

\section{INTRODUCTION}

Coumarins are common plant-derived natural products that are characterized by its core structure, coumarin (1, Figure 1). These molecules exhibit various biological activities such as antibacterial (Schinkovitz et al., 2003; Stavri et al., 2003; Céspedes et al., 2006), antioxidant (Bajerova et al., 2014), anti-inflammatory (Witaicenis et al., 2013), rodenticidal (Lotfi et al., 1996), termiticidal (Adfa et al., 2010, 2011), and other activities (Stahmann et al., 1941; Murray, 1989; Runkel et al., 1996; Song et al., 2014). In addition, the role(s) of coumarins in plants have also been reported. Scopoletin in tobacco is accumulated during a hypersensitive response (Gachon et al., 2004) and is considered to be involved in virus resistance (Chong et al., 2002). In Arabidopsis thaliana, coumarins play a role as a chelator of iron ions in soil (Fourcroy et al., 2013; Schmid et al., 2013; Schmidt et al., 2014).

Based on their structural and biosynthetic properties, plant coumarins are categorized as follows: simple coumarins, furanocoumarins, and pyranocoumarins, and coumarins with modifications in the pyrone ring (Figure 1) (Keating and O'kennedy, 1997). Simple coumarins harbor the hydroxy (-OH), alkoxy $(-\mathrm{OR})$, and/or alkyl $(-\mathrm{R}) \operatorname{group}(\mathrm{s})$ in their benzene ring: coumarin (1), umbelliferone (2: 7-hydroxycoumarin), esculetin (3: 6,7-dihydroxycoumarin), and scopoletin (4: 7-hydroxy-6methoxycoumarin). Their hydroxy group is involved in conjugation to produce glycosides (Tal and Robeson, 1986; Taguchi et al., 2000, 2001; Shimizu et al., 2005; Kai et al., 2006; Bayoumi et al., 2008b; Wu et al., 2009). Furanocoumarins and pyranocoumarins have additional ring systems, a five-or six-memberd ring with an oxygen atom, which are fused to the benzene ring.

Plant researchers consider coumarins as a potential fluorescent and flavoring component (Poulton et al., 1980; Oba et al., 1981; Mock et al., 1999; Katerinopoulos, 2004; Bourgaud et al., 2006; Stanfill et al., 2007; Maggi et al., 2011; Krieger et al., 2013). Tracer experiments using cinnamate (10) or its derivatives have effectively shown that simple coumarin formation in plants proceeds via hydroxylation of the ortho-position (ortho-hydroxylation) of respective cinnamates, the adjacent position in the benzene ring to the side chain (Brown et al., 1960; Brown, 1962; Fritig et al., 1970; Bayoumi et al., 2008a), followed by formation of a lactone ring. Furanocoumarins and pyranocoumarins are derived from umbelliferone (2) by addition of prenyl group (Larbat et al., 2007; Karamat et al., 2013). 4-Hydroxycoumarin (7) in Apiaceae and Asteraceae plants is presumed to utilize another biosynthetic pathway that does not require ortho-hydroxylation (Liu et al., 2009). It has been previously suggested that coumestrol (8) in Leguminosae plants, which also comprises a coumarin core structure, is synthesized from isoflavonoids, circumventing the need for ortho-hydroxylation of cinnamates in its biosynthetic pathway (Veitch, 2013).

Due to its irreversibility, ortho-hydroxylation is considered a key step in the biosynthesis of simple coumarins. This review summarizes the research findings on ortho-hydroxylation enzymes (ortho-hydroxylases) of cinnamates that are involved in simple coumarin biosynthesis. The distribution of the orthohydroxylases in plants using a database search of EST homologs will be also discussed.

\section{2-OXOGLUTARATE-DEPENDENT DIOXYGENASES INVOLVED IN THE ORTHO-HYDROXYLATION OF CINNAMATES ARE THE KEY ENZYMES OF SIMPLE COUMARIN BIOSYNTHESIS}

In Arabidopsis, a 2-oxoglutarate-dependent dioxygenase (2OGD) encoded by the gene AtFG'H1 (locus: At3g13610) was found to exhibit ortho-hydroxylase activity to feruloyl coenzyme A (15: feruloyl-CoA) as a substrate, with a $K_{m}$ value of $36 \mu \mathrm{M}$, yielding an ortho-hydroxylation product, 6-hydroxyferuloyl-CoA (19) (Kai et al., 2008). The AtF6' ${ }^{\prime} \mathrm{H}$ enzyme exhibits no catalytic activity to $p$-coumaroyl-CoA (14), free ferulic acid (13), or feruloyl 


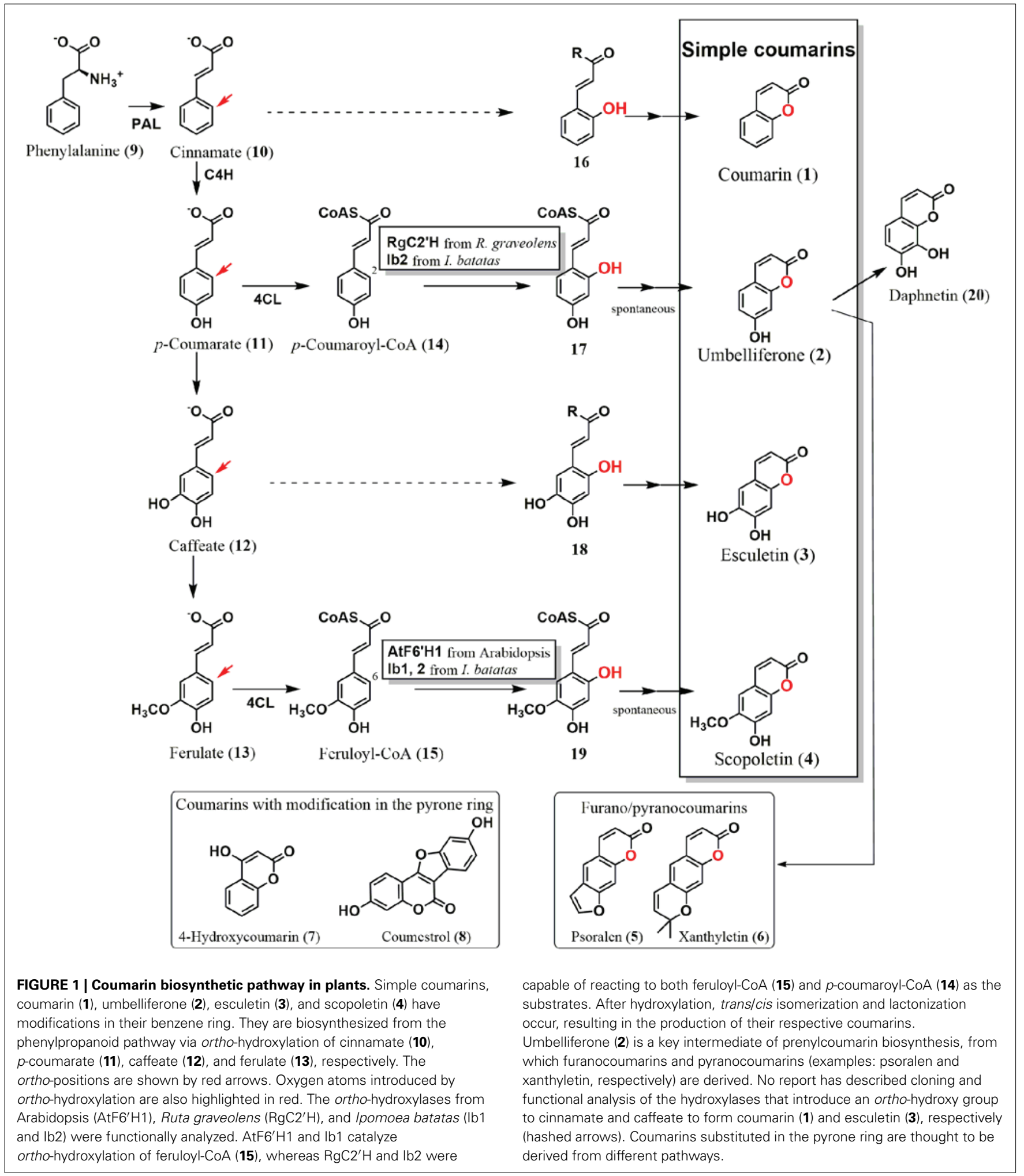

quinate. Deficient mutation of the AtF6'H1 gene in Arabidopsis causes a significant reduction in the accumulation of scopolin, a $\beta$-glucoside of scopoletin (4), indicating that $\mathrm{AtF}^{\prime} \mathrm{H1}$ catalyzes ortho-hydroxylation. Another 2OGD (AtF6 ${ }^{\prime} \mathrm{H} 2$ ) encoded by a homologous gene (locus: Atlg55290) exhibits an equivalent activity against CoA thioesters of cinnamates $\left(K_{m}\right.$ value for feruloyl-CoA: $14.5 \mu \mathrm{M}$ ); however, no significant change in scopolin levels was observed in the plant. 
Further studies involving cloning and functional analysis of the 2OGD genes in plants have elucidated the mechanism of coumarin formation. Using Ruta graveolenes, which accumulates franocoumarins, a $2 \mathrm{OGD}\left(\mathrm{RgC2}^{\prime} \mathrm{H}\right)$ was cloned as the key enzyme of coumarin biosynthesis (Vialart et al., 2011). $\mathrm{RgC2}^{\prime} \mathrm{H}$ shows hydroxylation activity not only to feruloylCoA $\left(15, K_{m}=37 \mu \mathrm{M}\right)$, but also to $p$-coumaroyl-CoA (14, $K_{m}=50 \mu \mathrm{M}$ ), forming scopoletin (4) and umbelliferone (2), respectively. Furanocoumarins are formed after addition of prenyl group to umbelliferone (2), which is detected in $R$. graveolens, whereas no scopoletin (4) was detected. This result indicates that $\mathrm{RgC}^{\prime} \mathrm{H}$ exclusively catalyzes $p$-coumaroyl-CoA (14), besides its activity against feruloyl-CoA (15) and p-coumaroyl-CoA (14). Regulation of substrate supply to $\mathrm{RgC}^{\prime} \mathrm{H}$ enzyme is likely to determine the structures of the products, namely, umbelliferone (2) or scopoletin (4).

The biosynthetic origin of the 1-oxygen atom of umbelliferone (2) in sweet potato root (Ipomoea batatas) is molecular oxygen; therefore, hydroxylase using a water molecule to introduce a hydroxy group was excluded as the candidate of ortho-hydroxylation enzyme(s) (Shimizu et al., 2008). 2OGDs from sweet potato were also cloned and functionally analyzed as the ortho-hydroxylases of CoA thioesters of the cinnamates (Matsumoto et al., 2011). The 2OGDs were then categorized into two groups based on their substrate specificities. Enzymes belonging to the first one, designated as Ib1s, showed ortho-hydroxylation activity to feruloyl-CoA (15, $K_{m}=$ approximately $\left.10 \mu \mathrm{M}\right)$, whereas those of Ib2s catalyzed both $p$-coumaroyl-CoA $\left(14, K_{m}=7.3-14 \mu \mathrm{M}\right)$ and feruloyl-CoA $\left(15, K_{m}=6.1-15.2 \mu \mathrm{M}\right)$ as the substrates to yield umbelliferone (2) and scopoletin (4), respectively. Root tissues of sweet potato accumulate moderate levels of scopolin. After fungal and elicitor treatments, the production of umbelliferone (2) and its $\beta$-glucoside, skimmin, was significantly higher than that before treatment, whereas the amount of scopolin remained at a moderate level after the treatments. Fungal and elicitor treatments also resulted in an upregulation of $I b 2$ genes, whereas no significant induction of $I b 1$ genes was detected. These results indicate that Ib2s mainly synthesize umbelliferone (2) using $p$-coumaroyl-CoA (14), besides their bi-functional activity.

In R. graveolens and I. batatas, the ortho-hydroxylases may act as neighboring enzymes by positioning themselves at enzymes of the upper steps such as $\mathrm{C} 4 \mathrm{H}, \mathrm{C} 3 \mathrm{H}$, or $4 \mathrm{CL}$, and receive more supplies with their substrate, p-coumaroyl-CoA (14), to produce umbelliferone (2). Interactions among the metabolic enzymes (Burbulis and Winkel-Shirdley, 1999) including the ortho-hydroxylases possibly occur when simple coumarins are biosynthesized in these plant cells.

The ortho-hydroxylase involved in the formation of coumarin (1) is still unknown, whereas approaches to biosynthesis of coumarin (1) have been performed using sweet clover (Gestetner and Conn, 1974) and lavender (Brown et al., 1960; Stoker and Bellis, 1962). Esculetin (3) formation is also remained to be elucidated. Ib1s from sweet potato showed a trace activity to caffeoyl-CoA (Matsumoto et al., 2011). Therefore, catalysis of these reactions by members of the 2OGD family is reasonable using cinnamate (10) or caffeate (12) esters, or their free acid, respectively. Enzymatic information of ortho-hydroxylase homologs would tell mechanism of these coumarins. There is still a possibility that other enzyme families such as flavin monooxygenases or another oxidase family would also contribute to this reaction (Schlaich, 2007). Furthermore, in cassava or chicory, modification steps involving the conversion of umbelliferone (2) to esculetin (3) or daphnetin (20: 7,8-dihydroxycoumarin) have been detected by tracer analysis, indicating a biosynthetic grid of simple coumarin formation (Sato and Hasegawa, 1972; Bayoumi et al., 2008a).

Although the details of the biosynthesis of simple coumarins are still unclear, the three examples of ortho-hydroxylases serve as key information for future researches on elucidating the mechanism of coumarin biosynthesis in plants. Substrate specificities of the ortho-hydroxylases from plants that accumulate coumarins will be also clue to know the metabolic grid of coumarin biosynthesis.

\section{QUEST FOR THE CANDIDATE SEQUENCES OF ORTHO-HYDROXYLASES IN PLANTS}

The substitution patterns involving the phenyl group of cinnamates have been extensively characterized. Furthermore, the CoA moiety is a prerequisite for their activity. The alignment of the amino acid sequences of previously reported orthohydroxylases is presented in Figure 2, which shows a moderately high sequence identity (approximately $59-64 \%$ amino acid identity), with conserved amino acid residues. Investigation of substrate specificities of 2OGDs using chimeric proteins revealed the significance of C-terminal sequence elements of gibberellin 20oxidases of Cucurbita maxima (Lange et al., 1997) and flavanone $3 \beta$-hydroxylase of Petunia sp. (Wellmann et al., 2004). They reported that the C-terminal sequences comprising 33-54 amino acid residues are involved in substrate recognition.

Taking advantage of these results, a TBLASTN search (http:// blast.ncbi.nlm.nih.gov/Blast.cgi; Altschul et al., 1997) was performed to explore candidate EST sequences of ortho-hydroxylases involved in the biosynthesis of simple coumarins, using the C-terminal sequences of $\mathrm{AtF}^{\prime} \mathrm{H} 1$ (54 amino acid residues, Supplementary Material 1).

The results (maximum target sequences: 1000; Supplementary Material 2) showed that the hit sequences belonged to the 2OGD family, with maximum scores within the range of $42-111$ and minimum $E$-values within the range of $1 \mathrm{e}^{-27}-1 \mathrm{e}^{-2}$. The highest scoring hits were observed in the Brassicales plants. Although it was necessary to analyze the accumulation of simple coumarins, these clones would show ortho-hydroxylase activity, thus indicating its involvement in simple coumarin formation. Plant species belonged to Spindales, Malvales, Malpigiales, Fabales, Rosales, Fagales, Vitales, Solanales, Lamiales, Gentianales, and Asteriales also showed significantly high scores and low E-values, whereas other plant species with 2OGD sequences were of relatively lower levels of similarity. In plants that accumulate simple coumarins, 2OGDs with higher levels of similarity are likely to exhibit ortho-hydroxylase activity. In Fabales, Lotus japonicus, Glycine max, Vigna unguiculata, and Medicago truncatula harbored ESTs with highly similar sequences. Coumarin is accumulated in Melilotus alba, a Fabales 
Ib $1-2$

Ib2-1-1

$\mathrm{RgC2} 2 \mathrm{H}$

AtF 6' H1

AtF 6' H2

Ibl-2

Ib2-1-1

$\mathrm{RgC} 2$ ' $\mathrm{H}$

AtF 6' H1

AtF 6' H2

Ib1-2

Ib2-1-1

$\mathrm{RgC} 2$ ' $\mathrm{H}$

AtF 6' H1

AtF 6 ' H2

Ib1-2

Ib2-1-1

RgC 2 ' $\mathrm{H}$

AtF 6' H 1

AtF 6' H2

Ib1-2

Ib2-1-1

$\mathrm{RgC} 2$ ' $\mathrm{H}$

AtF 6' H1

AtF 6' H2

Ib1-2

Ib2-1-1

RgC 2 ' $\mathrm{H}$

AtF 6 ' H 1

AtF 6' H2

Ib1-2

Ib2-1-1

$\mathrm{RgC} 2$ ' $\mathrm{H}$

AtF 6' H 1

AtF 6' H2
MP-AVLSSVLS------NITDFVVHEGNGVKGLADMGLEALPKQYVQPEEERITTSTVI- 52 MPSTTLSTVLS------DINEFVVKQGHGVKGLSELGLQTLPNQYVHPPEERLSSMDVV- 53 MAPTKDSVIHMGAESWDE ISEFVTKKGHGVKGLSELGIKTLPKOFHOPLEERFSEKKIL- 59 MAPTLLTTQFSNP---AEVTDFVVYKGNGVKGLSETGIKALPEQYIQPLEERLINKFVN- 56 MNQT-LAAQFLTR---DQVTNFVVHEGNGVKGLSETGIKVLPDQYIQPFEERLINFHVKE 56

* : : $\quad:: . * * .::^{*} * * * *:: *:: * * . *:: * * * *:$ :

-VDDTIPVIDLSEWGSDPKVGDMICEAAEKWGFFQIVNHGVPLEVLEEVKAATYRFFRLP 111 -SDDSIPVIDVSNWE-DPKVAKLICDAAEKRGFFOIVNHG IPLEMLEKAKAATYRFFREP 111 -ERASIPLIDMSKWD-SPEVVKSICDAAEHWGFFQIVNHGVPLETLQRVKEATHRFFALP 117 ETDEAIPVIDMSNPD-EDRVAEAVCDAAEKWGFFQV INHGVPLEVLDDVKAATHKFFNLP 115 DSDESIPVIDISNLD-EKSVSKAVCDAAEEWGFFOVINHGVSMEVLENMKTATHRFFGLP 115

$$
: * *: * *: *: \quad * \ldots,: *: * * * . * * * *:: * * *: .: * *: * * * *:: * * *
$$

AEEKNKHCKDNSPSNNVRYGTSFTPHAEKALEWKDFLSLFYVSDEEAAALWPSACRDEAL 171 AEEKKKYSKENCPTSHVRYSTSFLPQ IEKALEWKDHLSMFYVSDEEAAQYWPPSCRDDAL 171 AEEKNKYSKENSPINNVRFGSSFVPHVEKALEWKDFLSMFYVSEEETNTYWPPOCRDEML 177 VEEKRKFTKENSLSTTVRFGTSFSPLAEQALEWKDYLSLFFVSEAEAEOFWPDICRNETL 175 VEEKRKFSREKSLSTNVRFGTSFSPHAEKALEWKDYLSLFFVSEAEASQLWPDSCRSETL 175

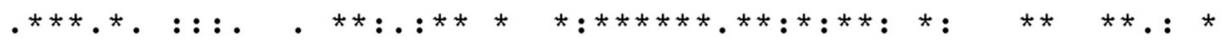

TFMRNCDAVIKRLLKSL-MKGLNVTE IDGTKESLLMGSKR INMNYYPKCPNPELTVGVGR 230 EYLKSCEMVSRKLLEAL-MOGLNVNE IDDAKE SLLMGSRR IN INYYPKCPNPDLTVGVGR 230 EYMRSSEVLIKRLMEVLVVKGLKVKO IDEIREPMLVGSRR INLNYYPKCPNPELTLGVGR 237 EY INKSKKMVRRLLEYL-GKNLNVKELDETKESLFMGS IRVNLNYYPICPNPDLTVGVGR 234 EYMNETKPLVKKLLRFL-GENLNVKELDKTKESFFMGSTRINLNYYPICPNPELTVGVGR 234

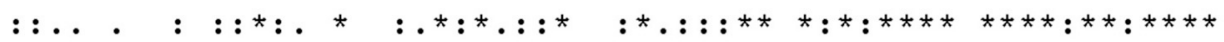

HSDVSTLTILLQDQIGGLYVRKLDS--DTWVHVPPINGAIVINVGDALQILSNGRYKS IE 288 HSDISTLTLLLQDDIGGLYVRKLEH--EAWSHVPPVKGALVINIGDALQIMSNGRYKS IE 288 HSDISTFTILLQDE IGGLHVRKLDDTGNTWVHVTPISGSLIINIGDALQIMSNGRYKS IE 297 HSDVSSLTILLODQIGGLHVRSLAS--GNWVHVPPVAGSFVINIGDAMOIMSNGLYKSVE 292 HSDVSSLTILLQDE IGGLHVRSLTT--GRWVHVPPISGSLVINIGDAMQIMSNGRYKSVE 292

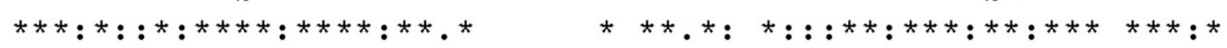

HRVIANGSNNRISVPIFVNPRPNDIIGPLPELLESGEKAVYKNVLYSDYVKHFFRKAHDG 348 HRVLANETNDRISVPVFVNPKPNDIVGPLPEVLASGEKPVYKPVLYSDYAKHFYRKAHNG 348 HMVVANGTODRISVPLFVNPKPQAILCPFPEVLANGEKPVYKPVLCSDYSRHFYTKPHDG 357 HRVLANGYNNRISVPIFVNPKPESVIGPLPEVIANGEEPIYRDVLYSDYVKYFFRKAHDG 352 HRVLANGS YNRISVPIFVSPKPESVIGPLLEVIENGEKPVYKDILYTDYVKHFFRKAHDG 352

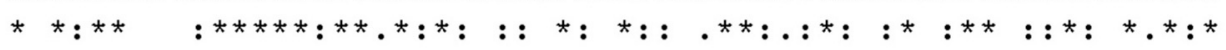

KETVDFAKIN 358

KDTIAFARIE 358

KKTVDFALMN 367

KKTVDYAKI- 361

KKTIDFANI- 361

*. : : * :

FIGURE 2 | Comparison of amino acid sequences of ortho-hydroxylases from the plants. Amino acid sequences are aligned using ClustalW2 (McWilliam et al., 2013, http://www.ebi.ac.uk/Tools/msa/clustalw2/). A FASTA file of the protein sequences is available as Supplementary Material 3. 
plant (Brown et al., 1960; Stoker and Bellis, 1962; Gestetner and Conn, 1974). These EST sequences in Fabales plants could serve as clues in the search for ortho-hydroxylases in cinnamate (10) from M. alba. In addition, sequences from Euphorbia spp. or Manihot esculenta, which accumulate esculetin (Masamoto et al., 2003; Bayoumi et al., 2008a; Nazemiyeh et al., 2009; Shi et al., 2009), showed high similarities. The biosynthetic pathway of simple coumarins containing esculetin in these plants would be elucidated through the functional analysis of these sequences. Species from the rest of the orders were less similar to the partial sequence of $\mathrm{AtF}^{\prime} \mathrm{H} 1$.

Kawai et al. (2014) conducted an extensive phylogenetic analysis of 2OGD sequences, where the ortho-hydroxylases involved in simple coumarin biosynthesis belonged to DOXC30-clade. These enzymes were not detected in Oryza sativa or other vascular plants that arose from more basal lineages (Stevens, 2014). There is no report about coumarin accumulation in O. sativa. The tendency decrease in the level of similarity in the EST sequences supports the results of the present study; therefore, it is unlikely that the hit sequences showing less similarity than that of $O$. sativa ( $\max$ score: 45 ; minimum $E$-value: $2 \mathrm{e}^{-4}$ ) exhibited ortho-hydroxylation of cinnamates to form simple coumarins. However, the boundary line dividing the ortho-hydroxylase sequence involved in simple coumarin biosynthesis and the other 2OGDs remains unclear. Liriodendron tulipifera, a Magnoliales plant that arose from a more basal lineage than monocots, accumulates scopoletin (4) (Kang et al., 2014). Cinnamomum cassia, which is Laureales plant, also contains coumarin (1) (Choi et al., 2001). However, no significant similarity in the C-terminal sequence of AtF6 ${ }^{\prime} \mathrm{H} 1$ was observed by TBLASTN search for ESTs in Magnoliales and Laurales plants. An unknown biosynthetic pathway of simple coumarins without 2OGD enzymes perhaps exists in plants.

Candidates of ortho-hydroxylases are mainly distributed in dicots, indicating that the biosynthesis of simple coumarins is a newer pathway of plant secondary metabolism, compared to flavonoids, which extensively occur in the plant kingdom (Harborne and Baxter, 1999; Williams and Grayer, 2004). Furthermore, biosynthetic pathways comprising apparently different enzyme sets evolutionally converged to form the coumarin core structure. Further analysis of plant ortho-hydroxylases at the molecular level would provide more details on the evolution of plant coumarins.

\section{ACKNOWLEDGMENTS}

The author would like to thank Dr. Ayako Yamaguchi for a fruitful discussion and Enago (www.enago.jp) for the English language review.

\section{SUPPLEMENTARY MATERIAL}

The Supplementary Material for this article can be found online at: http://www.frontiersin.org/journal/10.3389/fpls.2014. 00549/abstract

Supplementary Material 1 | The C-terminal sequences of the
ortho-hydroxylases involved in biosynthesis of simple coumarins.

Supplementary Material 2 | Results of TBLASTN search in EST sequences.

Supplementary Material 3 | FASTA file of the protein sequences.

\section{REFERENCES}

Adfa, M., Hattori, Y., Yoshimura, T., Komura, K., and Koketsu, M. (2011). Antifeedant and termiticidal activities of 6-alkoxycoumarins and related analogs against Coptotermes formosanus Shiraki. J. Chem. Ecol. 37, 598-606. doi: 10.1007/s10886-011-9968-6

Adfa, M., Yoshimura, T., Komura, K., and Koketsu, M. (2010). Antitermite activities of coumarin derivatives and scopoletin from Protium javanicum Burm. f. J. Chem. Ecol. 36, 720-726. doi: 10.1007/s10886-010-9807-1

Altschul, S. F., Madden, T. L., Schäffer, A. A., Zhang, J., Zhang, Z., Miller, W., et al. (1997). Gapped BLAST and PSI-BLAST: a new generation of protein database search programs. Nucleic Acids Res. 25, 3389-3402. doi: 10.1093/nar/25. 17.3389

Bajerova, P., Adam, M., Bajer, T., and Ventura, K. (2014). Comparison of various techniques for the extraction and determination of antioxidants in plants. J. Sep. Sci. 37, 835-844. doi: 10.1002/jssc.201301139

Bayoumi, S. A., Rowan, M. G., Beeching, J. R., and Blagbrough, I. S. (2008a). Investigation of biosynthetic pathways to hydroxycoumarins during postharvest physiological deterioration in Cassava roots by using stable isotope labelling. Chembiochem 9, 3013-3022. doi: 10.1002/cbic.200800515

Bayoumi, S. A., Rowan, M. G., Blagbrough, I. S., and Beeching, J. R. (2008b). Biosynthesis of scopoletin and scopolin in cassava roots during post-harvest physiological deterioration: the E-Z-isomerisation stage. Phytochemistry 69, 2928-2936. doi: 10.1016/j.phytochem.2008.09.023

Bourgaud, F., Hehn, A., Larbat, R., Doerper, S., Gontier, E., Kellner, S., et al. (2006). Biosynthesis of coumarins in plants: a major pathway still to be unravelled for cytochrome P450 enzymes. Phytochem. Rev. 5, 293-308. doi: 10.1007/s11101006-9040-2

Brown, S. A. (1962). Biosynthesis of coumarin and herniarin in lavender. Science 137, 977-978. doi: 10.1126/science.137.3534.977

Brown, S. A., Towers, G. H., and Wright, D. (1960). Biosynthesis of the coumarins. Tracer studies on coumarin formation in Hierochloe odorata and Melilotus officinalis. Can. J. Biochem. Physiol. 38, 143-156. doi: 10.1139/o60-016

Burbulis, I. E., and Winkel-Shirdley, B. (1999). Interactions among enzymes of the Arabidopsis flavonoid biosynthetic pathway. Proc. Natl. Acad. Sci. U.S.A. 96, 12929-12934. doi: 10.1073/pnas.96.22.12929

Céspedes, C. L., Avila, J. G., Martínez, A., Serrato, B., Calderón-Mugica, J. C., and Salgado-Garciglia, R. (2006). Antifungal and antibacterial activities of mexican tarragon (Tagetes lucida). J. Agric. Food Chem. 54, 3521-3527. doi: 10.1021/jf053071w

Choi, J., Lee, K. T., Ka, H., Jung, W. T., Jung, H. J., and Park, H. J. (2001). Constituents of the essential oil of the Cinnamomum cassia stem bark and the biological properties. Arch. Pharm. Res. 24, 418-423. doi: 10.1007/BF02 975187

Chong, J., Baltz, R., Schmitt, C., Beffa, R., Fritig, B., and Saindrenan, P. (2002). Downregulation of a pathogen-responsive tobacco UDP-Glc:phenylpropanoid glucosyltransferase reduces scopoletin glucoside accumulation, enhances oxidative stress, and weakens virus resistance. Plant Cell 14, 1093-1107. doi: 10.1105/tpc.010436

Fourcroy, P., Siso-Terraza, P., Sudre, D., Saviron, M., Reyt, G., Gaymard, F., et al. (2013). Involvement of the ABCG37 transporter in secretion of scopoletin and derivatives by Arabidopsis roots in response to iron deficiency. New Phytol. 201, 155-167. doi: 10.1111/nph.12471

Fritig, B., Hirth, L., and Ourisson, G. (1970). Biosynthesis of the coumarins: scopoletin formation in tobacco tissue cultures. Phytochemistry 9, 1963-1975. doi: 10.1016/S0031-9422(00)85348-0

Gachon, C., Baltz, R., and Saindrenan, P. (2004). Over-expression of a scopoletin glucosyltransferase in Nicotiana tabacum leads to precocious lesion formation during the hypersensitive response to tobacco mosaic virus but does not affect virus resistance. Plant Mol. Biol. 54, 137-146. doi: 10.1023/B:PLAN.0000028775.58537.fe

Gestetner, B., and Conn, E. E. (1974). The 2-hydroxylation of trans-cinnamic acid by chloroplasts from Melilotus alba Desr. Arch. Biochem. Biophys. 163, 617-624. doi: 10.1016/0003-9861(74)90522-0

Harborne, J. B., and Baxter, H. (1999). Handbook of Natural Flavonoids. Chichester: Wiley. ISBN: 0-471-95893-X

Kai, K., Mizutani, M., Kawamura, N., Yamamoto, R., Tamai, M., Yamaguchi, H., et al. (2008). Scopoletin is biosynthesized via ortho-hydroxylation of feruloyl CoA by a 2-oxoglutarate-dependent dioxygenase in Arabidopsis thaliana. Plant J. 55, 989-999. doi: 10.1111/j.1365-313X.2008.03568.x 
Kai, K., Shimizu, B., Mizutani, M., Watanabe, K., and Sakata, K. (2006). Accumulation of coumarins in Arabidopsis thaliana. Phytochemistry 67, 379-386. doi: 10.1016/j.phytochem.2005.11.006

Kang, Y. F., Liu, C. M., Kao, C. L., and Chen, C. Y. (2014). Antioxidant and anticancer constituents from the leaves of Liriodendron tulipifera. Molecules 19, 4234-4245. doi: 10.3390/molecules19044234

Karamat, F., Olry, A., Munakata, R., Koeduka, T., Sugiyama, A., Paris, C., et al. (2013). A coumarin-specific prenyltransferase catalyzes the crucial biosynthetic reaction for furanocoumarin formation in parsley. Plant J. 77, 627-638. doi: 10.1111/tpj.12409

Katerinopoulos, H. E. (2004). The coumarin moiety as chromophore of fluorescent ion indicators in biological systems. Curr. Pharm. Des. 10, 3835-3852. doi: $10.2174 / 1381612043382666$

Kawai, Y., Ono, E., and Mizutani, M. (2014). Evolution and diversity of the 2oxoglutarate-dependent dioxygenase superfamily in plants. Plant J. 78, 328-343. doi: $10.1111 /$ tpj. 12479

Keating, G. J., and O'kennedy, R. (1997). "The chemistry and occurrence of coumarins," in Coumarins: Biology, Applications and Mode of Action, eds R. O'kennedy and R. D. Thornes (Chichester: John Wiley \& Sons), 23-66. ISBN: 978-0-471-96997-6

Krieger, S., Hayen, H., and Schmitz, O. J. (2013). Quantification of coumarin in cinnamon and woodruff beverages using DIP-APCI-MS and LC-MS. Anal. Bioanal. Chem. 405, 8337-8345. doi: 10.1007/s00216-013-7238-x

Lange, T., Kegler, C., Hedden, P., Phillips, A. L., and Graebe, J. E. (1997). Molecular characterisation of gibberellin 20-oxidases. Structure-function studies on recombinant enzymes and chimaeric proteins. Physiol. Plant. 100, 543-549. doi: 10.1111/j.1399-3054.1997.tb03059.x

Larbat, R., Kellner, S., Specker, S., Hehn, A., Gontier, E., Hans, J., et al. (2007). Molecular cloning and functional characterization of psoralen synthase, the first committed monooxygenase of furanocoumarin biosynthesis. J. Biol. Chem. 282, 542-554. doi: 10.1074/jbc.M604762200

Liu, B., Raeth, T., Beuerle, T., and Beerhues, L. (2009). A novel 4-hydroxycoumarin biosynthetic pathway. Plant Mol. Biol. 72, 17-25. doi: 10.1007/s11103-0099548-0

Lotfi, H., Dreyfuss, M. F., Marquet, P., Debord, J., Merle, L., and Lachatre, G. (1996). A screening procedure for the determination of 13 oral anticoagulants and rodenticides. J. Anal. Toxicol. 20, 93-100. doi: 10.1093/jat,/20.2.93

Maggi, F., Barboni, L., Caprioli, G., Papa, F., Ricciutelli, M., Sagratini, G., et al. (2011). HPLC quantification of coumarin in bastard balm (Melittis melissophyllum L., Lamiaceae). Fitoterapia 82, 1215-1221. doi: 10.1016/j.fitote.2011. 08.011

Masamoto, Y., Ando, H., Murata, Y., Shimoishi, Y., Tada, M., and Takahata, K. (2003). Mushroom tyrosinase inhibitory activity of esculetin isolated from seeds of Euphorbia lathyris L. Biosci. Biotechnol. Biochem. 67, 631-634. doi: 10.1271/bbb.67.631

Stahmann, M. A., Huebner, C. F., and Link, K. P. (1941). Studies on the hemorrhagic sweet clover disease. V. Identification and synthesis of the hemorrhagic agent. J. Biol. Chem. 138, 513-527.

Matsumoto, S., Mizutani, M., Sakata, K., and Shimizu, B. (2011). Molecular cloning and functional analysis of the ortho-hydroxylases of $p$-coumaroyl coenzyme A/feruloyl coenzyme A involved in formation of umbelliferone and scopoletin in sweet potato, Ipomoea batatas (L.) Lam. Phytochemistry 74, 49-57. doi: 10.1016/j.phytochem.2011.11.009

McWilliam, H., Li, W., Uludag, M., Squizzato, S., Park, Y. M., Buso, N., et al. (2013). Analysis tool web services from the EMBL-EBI. Nucleic Acids Res. 41, W597-W600. doi: 10.1093/nar/gkt376

Sato, M., and Hasegawa, M. (1972). Biosynthesis of dihydroxycoumarins in Daphne odora and Cichorium intybus. Phytochemistry 11, 657-662. doi: 10.1016/00319422(72)80029-3

Mock, H. P., Heller, W., Molina, A., Neubohn, B., Sandermann, H. Jr., and Grimm, B. (1999). Expression of uroporphyrinogen decarboxylase or coproporphyrinogen oxidase antisense RNA in tobacco induces pathogen defense responses conferring increased resistance to tobacco mosaic virus. J. Biol. Chem. 274, 4231-4238. doi: 10.1074/jbc.274.7.4231

Murray, R. D. H. (1989). Coumarins. Nat. Prod. Rep. 6, 591-624. doi: 10.1039/np9890600591

Nazemiyeh, H., Kazemi, E. M., Zare, K., Jodari, M., Nahar, L., and Sarker, S. D. (2009). Free radical scavengers from the aerial parts of Euphorbia petiolata. J. Nat. Med. 64, 187-190. doi: 10.1007/s11418-009-0382-0
Oba, K., Conn, E. E., Canut, H., and Boudet, A. M. (1981). Subcellular localization of 2-( $\beta$-D-glucosyloxy)-cinnamic acids and the related $\beta$-glucosidase in leaves of Melilotus alba Desr. Plant Physiol. 68, 1359-1363. doi: 10.1104/pp.68.6.1359

Poulton, J. E., McRee, D. E., and Conn, E. E. (1980). Intercellular localization of two enzymes involved in coumarin biosynthesis in Melilotus alba. Plant Physiol. 65, 171-175. doi: 10.1104/pp.65.2.171

Runkel, M., Tegtmeier, M., and Legrum, W. (1996). Metabolic and analytical interactions of grapefruit juice and 1,2-benzopyrone (coumarin) in man. Eur. J. Clin. Pharmacol. 50, 225-230. doi: 10.1007/s002280050097

Schinkovitz, A., Gibson, S., Stavri, M., Cocksedge, M. J., and Bucar, F. (2003). Ostruthin: an antimycobacterial coumarin from the roots of Peucedanum ostruthium. Planta Med. 69, 369-371. doi: 10.1055/s-2003-38876

Schlaich, N. L. (2007). Flavin-containing monooxygenases in plants: looking beyond detox. Trends Plant Sci. 12, 412-418. doi: 10.1016/j.tplants.2007.08.009

Schmid, N. B., Giehl, R. F., Doll, S., Mock, H. P., Strehmel, N., Scheel, D., et al. (2013). Feruloyl-CoA 6'-hydroxylase1-dependent coumarins mediate iron acquisition from alkaline substrates in arabidopsis. Plant Physiol. 164, 160-172. doi: 10.1104/pp.113.228544

Schmidt, H., Gunther, C., Weber, M., Sporlein, C., Loscher, S., Bottcher, C., et al. (2014). Metabolome analysis of Arabidopsis thaliana roots identifies a key metabolic pathway for iron acquisition. PLoS ONE 9:e102444. doi: 10.1371/journal.pone.0102444

Shi, X. H., Luo, J. G., and Kong, L. Y. (2009). Coumarin glycosides from Euphorbia soongarica (Boiss). J. Asian Nat. Prod. Res. 11, 49-53. doi: 10.1080/10286020802436016

Shimizu, B., Kai, K., Tamai, M., Yamaguchi, H., Mizutani, M., and Sakata, K. (2008). Biosynthetic origin of the 1-oxygen of umbelliferone in the root tissue of sweet potato. Z. Naturforsch. C 63, 687-690. Available online at: http://www. znaturforsch.com/s63c/s63c0687.pdf

Shimizu, B., Miyagawa, H., Ueno, T., Sakata, K., Watanabe, K., and Ogawa, K. (2005). Morning glory systemically accumulates scopoletin and scopolin after interaction with Fusarium oxysporum. Z. Naturforsch. C 60, 83-90. Available online at: http://znaturforsch.com/ac/v60c/s60c0083.pdf

Song, B., Wang, Z., Liu, Y., Xu, S., Huang, G., Xiong, Y., et al. (2014). Immunosuppressive activity of daphnetin, one of coumarin derivatives, is mediated through suppression of NF-kappaB and NFAT signaling pathways in mouse T cells. PLoS ONE 9:e96502. doi: 10.1371/journal.pone.0096502

Stanfill, S. B., Brown, C. R., Yan, X. J., Watson, C. H., and Ashley, D. L. (2007) Quantification of flavor-related compounds in the unburned contents of bidi and clove cigarettes. J. Agric. Food Chem. 54, 8580-8588. doi: 10.1021/jf060733o

Stavri, M., Mathew, K. T., Bucar, F., and Gibson, S. (2003). Pangelin, an antimycobacterial coumarin from Ducrosia anethifolia. Planta Med. 69, 956-959. doi: $10.1055 / \mathrm{s}-2003-45109$

Stevens, P. F. (2014). Angiosperm Phylogeny Website. Version 13. Available online at: http://www.mobot.org/MOBOT/research/APweb/

Stoker, J. R., and Bellis, D. M. (1962). The biosynthesis of coumarin in Melilotus alba. J. Biol. Chem. 237, 2303-2305.

Taguchi, G., Fujikawa, S., Yazawa, T., Kodaira, R., Hayashida, N., Shimosaka, M., et al. (2000). Scopoletin uptake from culture medium and accumulation in the vacuoles after conversion to scopolin in 2,4-D-treated tobacco cells. Plant Sci. 151, 153-161. doi: 10.1016/S0168-9452(99)00212-5

Taguchi, G., Yazawa, T., Hayashida, N., and Okazaki, M. (2001). Molecular cloning and heterologous expression of novel glucosyltransferases from tobacco cultured cells that have broad substrate specificity and are induced by salicylic acid and auxin. Eur. J. Biochem. 268, 4086-4094. doi: 10.1046/j.14321327.2001.02325.x

Tal, B., and Robeson, D. J. (1986). The metabolism of sunflower phytoalexins ayapin and scopoletin: plant-fungus interactions. Plant Physiol. 82, 167-172. doi: $10.1104 /$ pp.82.1.167

Veitch, N. C. (2013). Isofiavonoids of the leguminosae. Nat. Prod. Rep. 30, 988-1027. doi: 10.1039/c3np70024k

Vialart, G., Hehn, A., Olry, A., Ito, K., Krieger, C., Larbat, R., et al. (2011). A 2-oxoglutarate-dependent dioxygenase from Ruta graveolens L. exhibits p-coumaroyl CoA $2^{\prime}$-hydroxylase activity $\left(\mathrm{C}^{\prime} \mathrm{H}\right)$ : a missing step in the synthesis of umbelliferone in plants. Plant J. 70, 460-470. doi: 10.1111/j.1365313X.2011.04879.x

Wellmann, F., Matern, U., and Lukacin, R. (2004). Significance of C-terminal sequence elements for Petunia flavanone 3 $\beta$-hydroxylase activity. FEBS Lett. 561, 149-154. doi: 10.1016/S0014-5793(04)00159-0 
Williams, C. A., and Grayer, R. J. (2004). Anthocyanins and other flavonoids. Nat. Prod. Rep. 21, 539-573. doi: 10.1039/b311404j

Witaicenis, A., Seito, L. N., Da Silveira Chagas, A., De Almeida, L. D. Jr., Luchini, A. C., Rodrigues-Orsi, P., et al. (2013). Antioxidant and intestinal antiinflammatory effects of plant-derived coumarin derivatives. Phytomedicine 21, 240-246. doi: 10.1016/j.phymed.2013.09.001

Wu, Q., Zou, L., Yang, X. W., and Fu, D. X. (2009). Novel sesquiterpene and coumarin constituents from the whole herbs of Crossostephium chinense. J. Asian. Nat. Prod. Res. 11, 85-90. doi: 10.1080/10286020802435703

Conflict of Interest Statement: The author declares that the research was conducted in the absence of any commercial or financial relationships that could be construed as a potential conflict of interest.
Received: 08 August 2014; accepted: 25 September 2014; published online: 03 November 2014.

Citation: Shimizu B-I (2014) 2-Oxoglutarate-dependent dioxygenases in the biosynthesis of simple coumarins. Front. Plant Sci. 5:549. doi: 10.3389/fpls.2014.00549

This article was submitted to Plant Metabolism and Chemodiversity, a section of the journal Frontiers in Plant Science.

Copyright (c) 2014 Shimizu. This is an open-access article distributed under the terms of the Creative Commons Attribution License (CCBY). The use, distribution or reproduction in other forums is permitted, provided the original author(s) or licensor are credited and that the original publication in this journal is cited, in accordance with accepted academic practice. No use, distribution or reproduction is permitted which does not comply with these terms. 